\title{
ACERCA DEL DOBLE CONCEPTO DE FILOSOFÍA Y LA SUPERVIVENCIA DEL PLURALISMO
}

\author{
Oscar NUDLER \\ CONICET/ Universidad Nacional del Comahue, Argentina
}

Si bien la reflexión o autorreflexión filosófica sobre la naturaleza o condición de la filosofía, y temas íntimamente asociados, como su lugar en el conjunto de los saberes o aun de la cultura en general, es una característica permanente de la actividad filosófica, sólo en algunas épocas asume un carácter focal, pasa a ser uno de los temas prioritarios de debate. En el siglo que acaba de terminar ocurrió así especialmente a raíz de la crítica radical del positivismo lógico a la filosofía tradicional. Sobrevino después un período de relativa calma, simultáneo con la decadencia del positivismo, pero a partir de fines de la década del 70 se produjo un nuevo florecimiento del tema. En Europa continental pensadores como Foucault o Derrida retomaron, desde un nuevo ángulo, la crítica de la tradición filosófica occidental y, dentro del ámbito anglosajón, fue sin duda Richard Rorty, con la publicación de su polémico libro La filosofia y el espejo de la naturaleza (Rorty, 1979) y trabajos posteriores ${ }^{1}$, quien más contribuyó a reavivar el debate sobre la condición de la filosofía y su papel en la cultura. En el curso de este ensayo intentaré recoger algunos hilos del debate entre Rorty y algunos de sus críticos, en particular Charles Taylor y Hilary Putnam, no por cierto para intentar un resumen o balance del mismo sino más bien como marco de referencia para introducir mi punto de vista sobre el asunto.

Comenzaré por señalar un componente de la posición de Rorty con el cual me encuentro en pleno acuerdo. Me refiero a su énfasis en el carácter históri-

1 Véase RORTY (1982) y su discusión con Habermas y otros filósofos sobre el estado de la filosofía en NIZNIK y SANDERS (eds.) (1996). 
co de la filosofía, es decir, en verla como un producto de una cultura dada la cultura occidental - en un tiempo dado y no como una manifestación necesaria y eterna de una supuesta naturaleza humana. Ahora bien, una vez aceptada la dependencia del desarrollo de la filosofía de ciertas condiciones, pareciera que uno no puede dejar de aceptar también como consecuencia la posibilidad de que un cambio cultural profundo pueda hacer que la filosofía occidental, al menos tal como la conocemos, pierda su razón histórica de ser, pase a ser culturalmente irrelevante. Y ello no necesariamente por una incapacidad o falta de interés de los practicantes de la filosofía para trasmitir sus ideas fuera del círculo especializado al que pertenecen sino por las nuevas condiciones de la cultura. Como es conocido, la opinión de Rorty es precisamente que la cultura occidental se encuentra en este punto, es decir, en el punto en que la filosofía se ha vuelto obsoleta.

Si bien acepto, como he mencionado, la tesis de Rorty acerca del carácter históricamente condicionado de la filosofía, no acepto sin embargo su conclusión acerca de la extinción o el fin de la filosofía. Creo que esta diferencia con Rorty proviene, como intentaré mostrar, del hecho de que él asume una noción a mi juicio demasiado estrecha o unilateral de la filosofía. Para explicar mi discrepancia parcial, aunque seria, con Rorty en este punto puede ser esclarecedor aludir, como anuncié más arriba, al debate que el filósofo norteamericano ha sostenido con algunos de sus críticos. Pero antes quisiera recordar la razón por la cual Rorty considera acabada a la filosofía tradicional, en particular la epistemología, que es la forma predominante que ha adquirido la filosofía en la modernidad, y adelantar una opinión al respecto. La mencionada razón reside en el carácter fundacionalista de la filosofía tradicional, carácter a partir del cual se desprende un autoasumido papel de juez de las pretensiones de verdad o aceptabilidad racional formuladas desde cualquier disciplina o campo de la cultura. Tal papel se ha vuelto, nos dice Rorty, claramente incompatible con la sociedad secularizada y pluralista que tenemos hoy en día, al menos en las democracias avanzadas de Occidente. La epistemología fue propia, según Rorty, de una época en que existía un consenso básico en la cultura acerca de ciertos rasgos supuestamente universales del conocimiento como lo es la existencia de un fundamento inmune a la duda pero tal consenso ha desaparecido en una sociedad como la actual, caracterizada, siempre según Rorty, por una multiplicidad de discursos inconmensurables. Sin embargo, creo que la visión histórica sobre la cual Rorty se apoya no es del todo adecuada. Aunque el tema requeriría un desarrollo más detallado, quisiera al 
menos señalar que la aparición y desarrollo de la filosofía occidental se volvió posible gracias a un conjunto de condiciones que se dieron en la cultura griega antigua y que permitieron desacralizar, aunque sea parcialmente, el tema del orden del mundo, natural y social, y someterlo a los avatares de la argumentación y el debate racional. Entre esas condiciones no se encontraba el consenso sino más bien, por una parte, la admisión, explícita o implícita dentro de la cultura, de un pluralismo de imágenes del mundo $y$, por la otra, la creencia en la posibilidad de un debate racional entre ellas. Cuando no se dieron o se debilitaron tales condiciones, la filosofía tendió a ceder su lugar a otras formas culturales o se hizo dependiente de ellas, como por ejemplo la religión, pero cuando reaparecieron la filosofía floreció nuevamente. El fundacionalismo sostenido por muchos filósofos, no todos, no impidió la existencia de un pluralismo dentro de la filosofía ni excluyó, por cierto, el debate racional, incluso sobre cuestiones de fundamentos.

Yendo pues al debate entre Rorty y sus críticos, es preciso distinguir en relación con estos entre quienes continúan defendiendo de algún modo al fundacionalismo, como por ejemplo los continuadores del primer Husserl, y quienes son tan antifundacionalistas como Rorty pero difieren de él por otras razones. Me concentraré sólo en estos últimos.

Entre los críticos post-fundacionalistas de Rorty hay a su vez posiciones bien distintas. Tomaré al respecto como ejemplos, según anticipé al comienzo, los casos de Taylor y Putnam, aunque hay desde luego muchos otros que también valdría la pena analizar en este contexto, desde Habermas y su defensa del proyecto ilustrado hasta el naturalismo quineano.

A pesar de sus diferencias, tanto Taylor como Putnam, y debo agregar por supuesto a Habermas, coinciden en considerar la concepción de Rorty de la filosofía tradicional o, al menos de parte de ella, como fundamentalmente equivocada. La naturaleza de la divergencia con Rorty se puede ver con claridad al examinar la actitud de cada uno de ellos hacia la filosofía kantiana. Para Rorty, Kant provee la versión más sofisticada y por tanto más insidiosa del fundacionalismo, cuyas manifestaciones clásicas son atribuidas a Descartes y, más atrás, por supuesto, a Platón. Pero los autores mencionados difieren radicalmente de Rorty en esta apreciación de Kant ya que reinvindican con énfasis la filosofía kantiana. A su vez, Taylor y Putnam también difieren de Rorty en su interpretación de la concepción de la filosofía del segundo Wittgenstein, pensador con quien todos los filósofos mencionados básicamente dicen acordar. 
Comenzando por Taylor, su posición coincide con la de Rorty en la necesidad, según sus palabras, de "superar" la epistemología. Pero discrepa con él sobre qué implica lograrlo. Para Taylor no se trata sólo de rechazar el fundacionalismo sino, más allá de ello, de reconstruir los vínculos indisolubles del sujeto del conocimiento con su mundo y su cuerpo, vínculos que el proyecto cartesiano había roto. Sólo a partir de la reconstrucción de tales vínculos se presentan lo que Kant considerara las condiciones de posibilidad del conocimiento. A su vez, la determinación de tales condiciones implica según Taylor el uso de una argumentación de tipo trascendental. Los argumentos trascendentales son de carácter regresivo, comienzan a partir de la afirmación del carácter indudable de algún rasgo de nuestra experiencia y prosiguen con la deducción de las condiciones subjetivas de su constitución. Esta estrategia argumentativa introducida por Kant es la que verdaderamete lleva a cabo, de acuerdo con Taylor, la superación de la epistemología, de su fundacionalismo y de su concepción representacionalista del conocimiento, según la cual el sujeto toma distancia del mundo y de su cuerpo, los objetiva y a partir de allí se propone construir una representación exacta de él. Taylor llega de este modo a una posición que lo aproxima a filósofos como Heidegger, con su postulación de la indisolubilidad de la relación ser humano-mundo, Merleau-Ponty y su fenomenología antidualista de la percepción, y Gadamer, con su concepción de la tradición como fondo omnipresente de toda figura que traza el conocimiento. Pero también, como mencionamos, Taylor declara su afinidad con Wittgenstein y su descripción del lenguaje como arraigado en la forma de vida. A partir de tal arraigo se desprende, como Wittgenstein lo ha subrayado, la imposibilidad de hallar fundamentos últimos en una esfera conceptual supuestamente separada y descontextualizada.

Es posible sin embargo dudar de que Taylor efectivamente haya logrado mostrar que Kant, por el hecho de usar argumentos trascendentales, no es fundacionalista. Podría aducirse que lo que Kant ha producido es sólo una variante del fundacionalismo, la variante trascendental. El hecho mismo de que las condiciones de posibilidad no sean asumidas por Kant con carácter hipotético sino decididamente apodíctico, abona en favor de la segunda alternativa. Así pues, la crítica de Taylor a la lectura de Kant que hace Rorty no sería, al menos en este punto, aceptable. Pero, sea como fuere, lo que más me interesa destacar en relación con nuestro tema es que Taylor omite considerar un aspecto de la herencia kantiana que es desde mi punto de vista fundamental y que ha sido fuertemente enfatizado en cambio por Putnam. Kant, en efecto, presenta 
en la Crítica de la Razón Pura un doble concepto de la filosofía, filosofía como Schulbegriff y filosofía como Weltbegriff. De acuerdo con el primer concepto, la filosofía es, dice Kant, un saber escolástico, un sistema de conocimiento que se intenta construir a la manera de la ciencia, dotado de la unidad sistemática y el rigor propios de ésta. Taylor parece atender sólo a este primer concepto, la filosofía como ciencia pura del dominio trascendental de la razón, descuidando el segundo concepto. De acuerdo con este segundo concepto, que Kant denomina un conceptus cosmicus, la filosofía está ligada con el ideal del filósofo para quien la filosofía está al servicio, nos dice, de «los fines esenciales de la razón humana". Tales fines aparecen según Kant bajo la forma de cuestiones que la razón humana necesariamente se plantea pero que sin embargo es incapaz de responder. "La razón humana (se lee en un célebre pasaje de la CRP tiene como destino peculiar [...] estar cargada de cuestiones que, al estar prescriptas por su propia naturaleza, no puede ignorar pero que, al trascender sus poderes, tampoco puede responder" (Kant, CRP, A838-839). El filósofo no debería según Kant prescindir de ninguno de los dos conceptos de filosofía. Su tarea es así hacer explícitas de un modo riguroso las condiciones de posibilidad del conocimiento y, al mismo tiempo, poner de manifiesto el carácter paradójico o aporético de los constituyentes de la Weltbegriff, mostrando de esta manera el límite entre lo que es o puede ser conocimiento y lo que sólo es ilusión trascendental.

Ahora bien, tomando esta concepción kantiana de la filosofía como tensión entre dos conceptos opuestos pero que se requieren mutuamente, concepción con la cual, a partir de cierto momento de su trayectoria intelectual, expresa su pleno acuerdo, Putnam critica, por un lado, a los filósofos analíticos que sólo toman en cuenta el primer concepto de filosofía y la consideran así exclusivamente a la manera de una ciencia, como una disciplina rigurosa dotada de un lenguaje técnico reservado a especialistas. $Y$, por otra parte, critica a los filósofos, entre los cuales alinea precisamente a Rorty, que consideran que una vez que se ha mostrado que los llamados "problemas filosóficos" son en realidad producto de confusiones conceptuales tales problemas, simplemente desaparecen. Esta diferencia entre Putnam y Rorty aparece también claramente a través de la manera en que cada uno de ellos interpreta el pensamiento del segundo Wittgenstein en este sentido. Para Rorty, quien favorece una interpretación que se podría llamar standard de las Investigaciones Filosóficas, Wittgenstein ha mostrado el camino para librarnos definitivamente de los problemas filosóficos y, según la conocida formulación wittgensteiniana, lograr la paz que produce su 
disolución. Putnam sostiene en cambio, siguiendo a Cavell, que lo que Wittgenstein quiso en realidad significar es que tal estado de paz sólo puede ser momentáneo, que siempre surgen nuevos problemas filosóficos porque su constante resurgir está asociado con la naturaleza misma del lenguaje. La filosofía, según dice Wittgenstein en un pasaje con resonancias kantianas, choca con los límites del lenguaje y de este modo nos muestra algo profundo acerca de la naturaleza de aquél.

Independientemente de la debatida cuestión acerca de cuál es la interpretación correcta del pensamiento de Wittgenstein sobre la filosofía y su posible afinidad con Kant, hay dos puntos que a esta altura creo necesario plantear. En primer lugar, coincidir con Putnam en cuanto al valor elucidatorio del doble concepto kantiano. Pero, en segundo lugar, subrayar que no me siento convencido por un aspecto de la doctrina kantiana, aparentemente endosado por Putnam, según el cual dicho valor se funda en el arraigo del doble carácter de la filosofía en algo así como la naturaleza humana, la naturaleza de la mente o el lenguaje. Como señalé al comienzo, creo como Rorty que la existencia y continuidad de la filosofía en la cultura no se puede atribuir simplemente a una supuesta necesidad filosófica permanente del ser humano. Aún si tal necesidad existiera, la filosofía como institución cultural seguiriá siendo compatible con y, más aún, funcional a sólo ciertos contextos históricos y culturales y no a otros.

A fin de mostrar a través de un ejemplo concreto el alcance de lo dicho hasta aquí, esbozaré la manera en que aparece la filosofía de Platón cuando es vista desde la óptica del doble concepto kantiano. Se trata de un ejemplo especialmente interesante ya que los dos conceptos de filosofía operan en la obra de Platón separadamente, no se encuentran integrados entre sí como quería Kant. Tal diferencia entre los dos conceptos que pueden discernirse en los textos platónicos ha sido formulada en detalle y defendida con énfasis por Gregory Vlastos en su último libro (Vlastos, 1991), aunque no la refiera explícitamente a Kant. Nos referimos a la distinción neta que traza Vlastos entre el Sócrates de los primeros Diálogos platónicos y el Sócrates posterior, distinción tal vez demasiado tajante (pues se pueden encontrar pasajes de este último que recuerdan al primero( pero, de todos modos, a mi juicio básicamente correcta. Vlastos resume en diez tesis las diferencias entre los dos Sócrates pero me limitaré a tomar las dos más importantes. De acuerdo con una de las tesis, el primer Sócrates, si bien busca el conocimiento, lo hace exclusivamente a través del diálogo llamado «elénjico» o refutatorio, que de hecho siempre 
termina de modo abierto, habiendo rechazado diversas respuestas pero sin haber alcanzado ninguna considerada satisfactoria a la cuestión planteada. El segundo Sócrates, en cambio, busca un conocimiento demostrativo y confía en haberlo hallado. De acuerdo con la otra tesis de Vlastos, directamente vinculada con la anterior, el primer Sócrates no reinvindica la posesión de ningún conocimiento filosófico sino, por el contrario, proclama su ignorancia. En cambio, el segundo Sócrates defiende una doctrina filosófica positiva, la teoría metafísica de las Formas, a las cuales dota de una existencia separada, y de un alma que asciende hacia un conocimiento, aunque sea parcial, de esas Formas.

Si echamos una rápida mirada al contexto histórico en que se dio la mencionada diferencia entre los dos Sócrates - la Atenas de fines del siglo $\mathrm{V}$ y principios del IV, encontramos una ciudad multicultural y pluralista en que había, como sugerimos antes, una competencia abierta y relativamente pacífica entre diferentes imágenes del mundo, escalas de valores y prácticas sociales asociadas. Lo que el Sócrates de los primeros Diálogos planteó en ese escenario, que ya había entrado en crisis a raíz de las guerras del Peloponeso y la derrota de Atenas frente a Esparta, fueron preguntas relativas a la naturaleza de las virtudes, es decir, de los valores en torno de los cuales gira el significado de la existencia humana, y un procedimiento para responderlas que no presuponía la verdad de ninguna de las respuestas disponibles. La práctica dialógica socrática implicaba, en relación con las cuestiones planteadas, un examen de las mismas que conducía invariablemente, como hemos mencionado, a una aporía resultante de una invalidación de todas las propuestas de solución planteadas, propuestas que básicamente correspondían a creencias típicas de distintos grupos de la sociedad griega. Pero tal resultado, y la autoproclamada ignorancia socrática, no suponía ni escepticismo ni relativismo sino, por el contrario, la creencia en la posibilidad de alcanzar un conocimiento racional incondicionado de la naturaleza de las virtudes. Por otra parte, la ignorancia socrática, como lo han puesto de manifiesto diversos estudios a través de la última década, no estaba referida al conocimiento en general sino sólo al conocimiento experto de las virtudes, como lo destaca Woodruff (1990), o, como lo plantean Brickhouse y Smith (1994), al conocimiento que no es sólo conocimiento sino también sabiduria.

Traspuesto a un lenguaje kantiano, lo que Sócrates proponía a sus interlocutores era una búsqueda de un conocimiento de los fines esenciales de la razón humana, es decir, una filosofía como Weltbegriff. $\mathrm{Y}$, al intentar construir tal conocimiento Sócrates muestra, al igual que Kant, que se desemboca en la 
incertidumbre aporética, aunque lo muestra no como éste a través de consideraciones teóricas sino de un modo práctico, simplemente intentándolo. Es claro a mi juicio que esta filosofía socrática es funcional al propósito de construir significados compartidos en una sociedad heterogénea, multicultural. $\mathrm{Y}$ lo es no sólo porque incita al diálogo entre individuos con distintos esquemas conceptuales sino sobre todo porque procura conducirlos a un territorio común —el de la ignorancia socrática — desde el cual se vuelve posible apreciar los límites de sus esquemas y convicciones particulares en relación con el problema práctico de determinar cómo debemos vivir. Es decir, Sócrates no rechaza las tradiciones, ni las tradiciones religiosas, ni la de los filósofos o científicos de la naturaleza (sólo dice al respecto que él no se ocupa del tema), y reconoce y respeta además el conocimiento embebido en las artes prácticas. Sólo ataca la hubris que impide apreciar sus límites mostrando que no pueden responder al problema de dar una definición (en el sentido socrático de definición) aceptable de las virtudes. Y, al no tener él mismo ninguna para ofrecer, plantea la filosofía no como una doctrina sino como una actividad de carácter inquisitivo acerca de enigmas que son de interés, de máximo interés, para todos los hombres sin excepción, independientemente de la herencia, ubicación y prácticas sociales en que estén inmersos.

Por el contrario, la otra manera típica en que el filósofo procede en una sociedad multicultural, propia del segundo Sócrates, o sea de Platón, es desarrollar un esquema o sistema conceptual que ofrece como alternativa superior a todas las existentes. Esta manera de hacer filosofía, correspondiente exclusivamente al primer concepto de Kant, puede presentarse, como en el mismo Platón, bajo la forma de un sistema metafísico independiente o puede hallarse en una relación estrecha, a veces de subordinación, respecto de otro saber, la teología en la Edad Media o la ciencia en la época moderna. Pero, sea como fuere, su éxito en términos de dominación social es a la larga incompatible con la supervivencia del pluralismo y la tolerancia de una sociedad liberal, como queda paradigmáticamente ilustrado por la República de Platón. Si es ésta la concepción de la filosofía que Rorty tiene en mente, y es fácil ver que efectivamente lo es, hay que reconocer que tiene razón en cuanto a que su dominación cultural sería incompatible con una sociedad liberal. Pero, como se mencionó, se trata en mi opinión de un concepto indebidamente estrecho, unilateral, de la filosoffa según el cual ésta no es controlada, en su búsqueda de un conocimiento riguroso, por otro concepto capaz de aportar una conciencia del carácter paradójico de los problemas límite que la filosofía al mismo tiempo genera. 
Si tomamos pues en cuenta el doble concepto de filosofía, ésta aparece no ya como un residuo sin vida proveniente del pasado, ni como una especialidad esotérica sin impacto fuera del círculo de sus cultores, sino como un modo del pensar estrechamente vinculado a la supervivencia de una sociedad pluralista. Dicho de otro modo, la filosofía entendida y practicada de acuerdo con este doble concepto, podría y debería contribuir a desactivar las dos formas de barbarie que hoy amenazan simultáneamente a la democracia: la intolerancia enraizada en imágenes totalizantes $u$ acríticas del mundo y la hubris tecnocrática.

\section{Referencias bibliográficas}

BrickHouse, T. C. \& Smith, N. D. (1994), Plato's Socrates, Oxford and New York: Oxford University Press.

Kant, I. (1781), Kritik der reinen Vernunft (trad. cast.: Crítica de la Razón Pura, Buenos Aires: Losada, 1960).

NizNIK, J. y Sanders, J. T. (eds) (1996), Debating the State of Philosophy: Habermas, Rorty, and Kolakowski, Wesport, Connecticut \& London, Praeger.

Nudler, O. (1996), «Problemas Filosóficos y Filosofias del Límite», Cadernos de Historia e Filosofia da Ciencia, Centro de Lógica, Epistemología e Historia de la Ciencia, Unicamp, serie 3, vol. 6.

Putnam, H. (edited by James Conant) (1992), Realism with a Human Face, Cambridge, Mass., Harvard University Press.

RoRTy, R. (1979), Philosophy and the Mirror of Nature, Princeton, New Yersey: Princeton University Press.

- (1982), Consequences of Pragmatism, Minneapolis: University of Minnesota Press. TAYLOR, Ch. (1995), Philosophical Arguments, Cambridge, Mass.: Harvard University Press.

VLASTOS, G. (1991), Socrates: Ironist and Moral Philosopher, Ithaca, New York: Cornell University Press.

WoOdRufF, P. (1990), "Plato's Early Theory of Knowledge», en S. Everson (ed.), Companions to Ancient Thought I: Epistemology, 60-84, Cambridge. 